Trinity University

Digital Commons @ Trinity

Chemistry Faculty Research

Chemistry Department

2011

\title{
Antiaromatic Dianions: Dianions of Dixanthylidene by Reduction and Attempted Excited-State Deprotonation
}

Mary Black

Trinity University

Clifford Woodford

Trinity University

Nancy S. Mills

TrinityUniversity,nmills@trinity.edu

Follow this and additional works at: https://digitalcommons.trinity.edu/chem_faculty

Part of the Chemistry Commons

\section{Repository Citation}

Black, M., Woodford, C., \& Mills, N. S. (2011). Antiaromatic dianions: Dianions of dixanthylidene by reduction and attempted excited-state deprotonation. Journal of Organic Chemistry, 76(7), 2286-2290. doi:10.1021/jo102449y

This Article is brought to you for free and open access by the Chemistry Department at Digital Commons @ Trinity. It has been accepted for inclusion in Chemistry Faculty Research by an authorized administrator of Digital Commons @ Trinity. For more information, please contact jcostanz@trinity.edu. 


\title{
Antiaromatic Dianions: Dianions of Dixanthylidene by Reduction and Attempted Excited-State Deprotonation
}

\author{
Mary Black, Clifford Woodford, and Nancy S. Mills* \\ Department of Chemistry, Trinity University, San Antonio, Texas 78212, United States
}

Supporting Information

ABSTRACT: Reduction of dixanthylidene with potassium or lithium resulted in formation of the antiaromatic dianion in high yield. Attempts to form the dianion by excited-state deprotonation of dixanthene with $n$-butyllithium/TMEDA resulted in formation of the tetraanion from deprotonation ortho to the oxygen. Orientation of the $\mathrm{sp}^{3}$ hydrogens presumably allows preferential deprotonation of the xanthene rings.

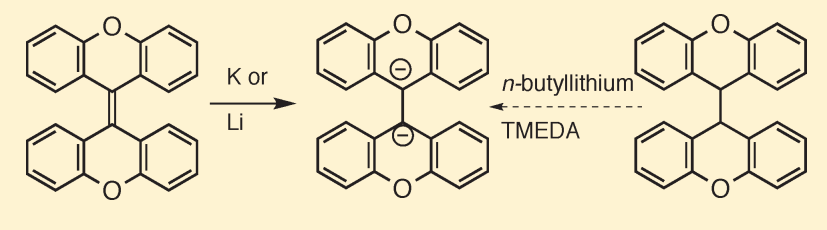

$\mathrm{W}$ e have been involved in the preparation of antiaromatic dications via oxidation of unsaturated precursors ${ }^{1-8}$ and ionization of diols for some time. ${ }^{9,10}$ The antiaromaticity of these species can be evaluated by the same type of criteria used in the evaluation of aromatic compounds. Those criteria are magnetic, including ${ }^{1} \mathrm{H}$ NMR shifts, ${ }^{11}$ nucleus-independent chemical shifts, ${ }^{12}$ and magnetic susceptibility exaltation; ${ }^{13}$ energetic, including aromatic stabilization energy; ${ }^{14}$ and structural, including the degree of bond length alternation. ${ }^{15}$ While these criteria have not always provided consistent answers to the relative aromaticity of compounds, ${ }^{16,17}$ the inclusion of antiaromatic species can provide greater clarity to the relationships between the criteria because the range of measurements becomes larger. Focusing only on magnetic measures, the proton chemical shifts for neutral aromatic species are usually found between 6.5 and $8.5 \mathrm{ppm}$; the addition of antiaromatic dications can give ranges beginning as high as $4.97 ;^{\circ}$ antiaromatic dianions give ranges which begin as high as 2.58 ppm. ${ }^{18}$ Magnetic susceptibility exaltation is known to be dependent on the area of the ring system; ${ }^{19}$ the extension of range provided by the inclusion of antiaromatic species has allowed the relationship between magnetic susceptibility exaltation and the nucleus independent chemical shift to confirm a similar dependence on the area of the ring system for the nucleus independent chemical shift. ${ }^{20}$

While the bulk of our work has been on antiaromatic dications, we have begun to explore the antiaromaticity of dianions such as the dianion of tetrabenzo[5.7] fulvalene, ${ }^{18}$ which we prepared by reduction of the neutral precursor. The success of this mode of formation suggested that the following suite of dianions, $\mathbf{1}^{\mathbf{2}-}$ $3^{2-}$ might provide an avenue to a variety of additional antiaromatic dianions. Dianion $3^{2-}$ has been implicated in reactions but has never been characterized spectroscopically; ${ }^{21,22}$ the experimental preparations of $\mathbf{1}^{\mathbf{2 -}}$ and $\mathbf{2}^{\mathbf{2 -}}$ have not been reported in the literature. The calculated structures of $1^{2-}-3^{2-}$ are very similar in the following respects. All three dianions consist of two planar ring systems, which are perpendicular to each other; see Supporting Information. The phenyl substituents in $2^{2-}$ are each perpendicular to the planar aza-anthracene system. The corresponding monoanions, e.g., 4, also possess planar ring systems; see the Supporting Information.
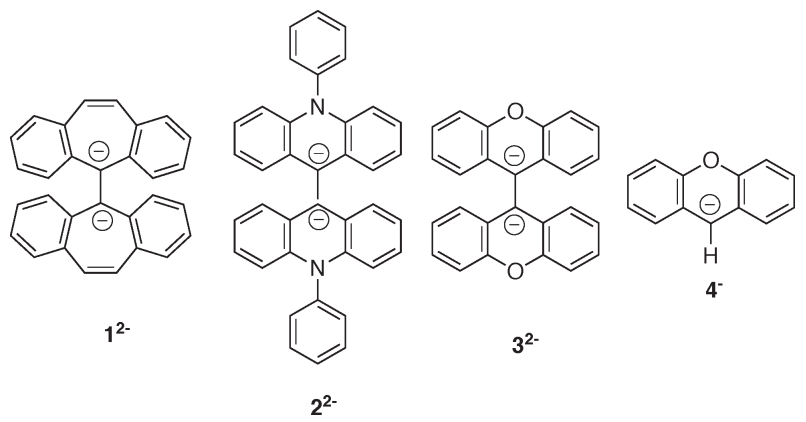

Measures of Antiaromaticity. Nucleus-Independent Chemical Shift. The nucleus-independent chemical shifts, NICS, provide a measure of aromaticity/antiaromaticity through a probe of the magnetic region in the center of a ring current. ${ }^{12}$ The calculated chemical shift of this probe uses the tensor perpendicular to the planar ring system and is known as the NICS $(1)_{z z}$ value. ${ }^{23}$ Negative NICS values indicate aromaticity; positive values, antiaromaticity. The NICS $(1)_{z z}$ values for dianions $\mathbf{1}^{2-}-3^{2-}$ and monoanion $4^{-}$ are given in Table 1 . Thus, the all-carbon system $\mathbf{1}^{2-}$ is the most antiaromatic, with the antiaromaticity decreasing as the heteroatom becomes more electronegative.

Magnetic Susceptibility Exaltation. A second measure of aromaticity/antiaromaticity is the exaltation of the magnetic susceptibility that is caused by the response of the ring current to the magnetic field. ${ }^{19,24,25}$ The magnetic susceptibility exaltation, $\Lambda$, can be determined by subtracting the sum of the magnetic susceptibilities of the bonds in a molecule or ion from the magnetic susceptibility of the delocalized system. The exaltation for $\mathbf{1}^{2-}-3^{2-}$ is given in Table 1 and shows the same

Received: December 14, 2010

Published: March 09, 2011 
Table 1. Nucleus-Independent Chemical Shifts ${ }^{a}, \operatorname{NICS}(1)_{z z}$, and Magnetic Susceptibility Exaltation, ${ }^{b} \Lambda$, for $1^{2-}-3^{2-}$ and $4^{-}$

\begin{tabular}{lrccr} 
& central ring & outer rings & $\sum \operatorname{NICS}(1)_{z z}{ }^{c}$ & \multicolumn{1}{c}{$\Lambda$} \\
$\mathbf{1}^{2-}$ & 104.67 & 38.07 & 361.60 & 236.14 \\
$\mathbf{2}^{2-}$ & 33.81 & 11.28 & 112.76 & 75.43 \\
$\mathbf{3}^{2-}$ & 32.77 & 1.04 & 69.68 & 33.02 \\
$\mathbf{4}^{-}$ & 9.87 & 0.65 & 11.17 & 24.37
\end{tabular}

${ }^{a}$ Calculated with the GIAO method and basis set B3LYP/6-311+g(d,p) on geometries optimized at the B3LYP/6-31 g(d) level. ${ }^{b}$ Calculated with the CSGT method and basis set B3LYP/6-311+g(d,p) on geometries optimized at the B3LYP/6-31 g(d) level. ${ }^{c}$ Summation for entire system.

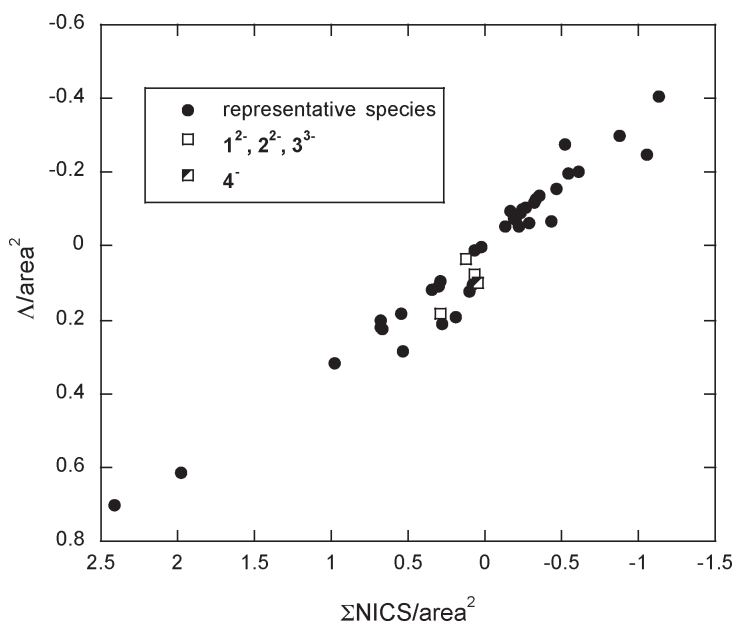

Figure 1. Magnetic susceptibility exaltation/square area vs $\Sigma$ NICS$(1)_{z z}$ /square area for $\mathbf{1}^{2-}-3^{2-}$ and $4^{-20}$

decrease in antiaromaticity shown by the $\Sigma \mathrm{NICS}(1)_{z z}$; see the Supporting Information for details of the calculations. We have previously shown a linear relationship between $\Sigma \mathrm{NICS}(1)_{z z} /$ square area and $\Lambda$ /square area. ${ }^{20}$ That plot is given in Figure 1 for a series of aromatic and antiaromatic ions and neutral compounds. Dianions $\mathbf{1}^{2-}-3^{2-}$ and monoanion $4^{-}$show the same relationship as the larger group of neutral compounds and anions that was taken from the previous study.

Comparison of the Antiaromaticity of Dianion $3^{2-}$ with Monoanion $4^{-}$. Because $3^{2-}$ is the first antiaromatic heterocyclic dianion for which structural evidence exists, it is appropriate to compare it with the corresponding monoanion $4^{-} \cdot{ }^{1} \mathrm{H}$ NMR spectral data for $4^{-}$has been reported ${ }^{26,27}$ and is included in the Supporting Information. The average ${ }^{1} \mathrm{H}$ chemical shift for $4^{-}$from deprotonation with $\mathrm{KH}$ in DMSO- $d_{6}$ is $5.428 \mathrm{ppm}$; that of $\mathrm{K}_{2} 3$ is $5.242 \mathrm{ppm}$, vide infra. While it is difficult to compare chemical shifts in different solvents, this data suggests slightly greater antiaromaticity for the dianion over the corresponding monanion. This is consistent with the increased antiaromaticity of the dication of tetrabenzo[5.5] fulvalene, ${ }^{8}$ in comparison with the corresponding fluorenyl monocation. ${ }^{28}$ The calculated NICS values of dianion $3^{2-}$ were more positive, supporting its greater antiaromaticity, than those of the corresponding monoanion $4^{-}$, when evaluated per ring system. It appears that this relationship is not consistent with the magnetic susceptibility data of $4^{-}$ compared to a single ring system of $3^{2-}$. However, Figure 1
Scheme 1. Preparation of $3^{2-}$ by Reduction

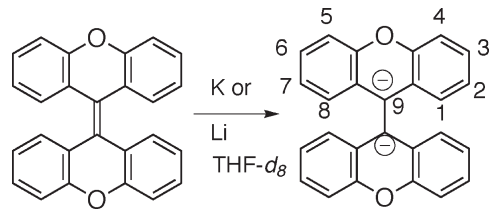

a)

b)
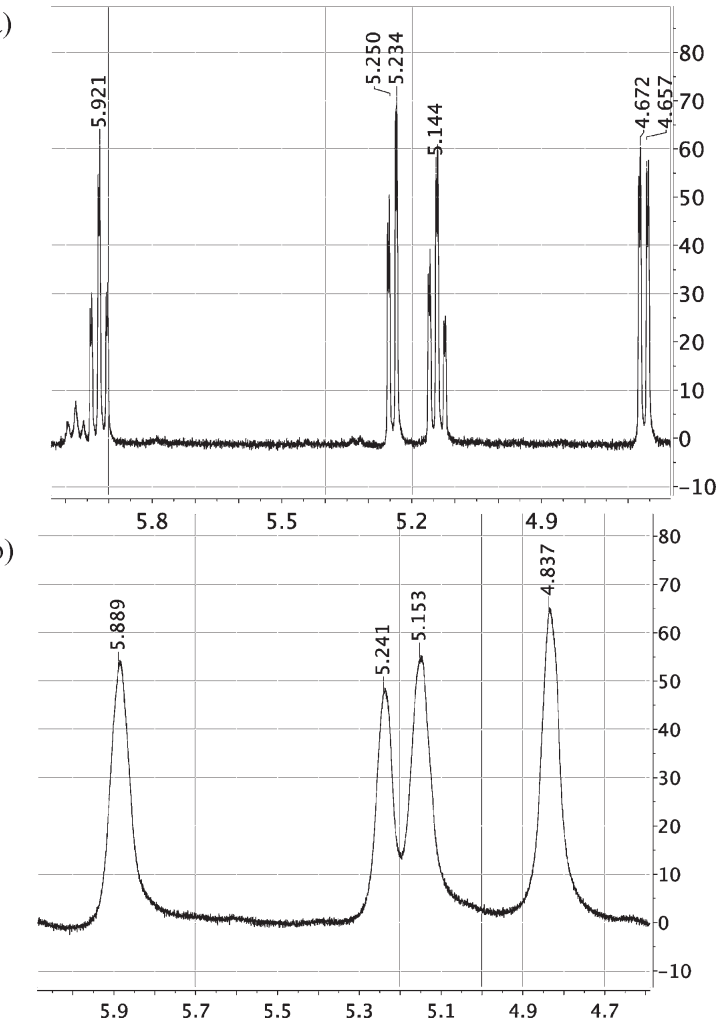

Figure 2. Reduction of dixanthylidene. (a) Reduction with potassium. (b) Reduction with lithium.

suggests that this inconsistency does not affect the relationship between the $\Sigma$ NICS/square area and $\Lambda$ /square area. A probable explanation lies in the relatively small degree of antiaromaticity in both $3^{2-}$ and $4^{-}$in comparison with other antiaromatic dications and dianions studied.

Preparation of the Dianion of Dixanthylidene by Reduction. Reduction of dixanthylidene, 3, with either lithium or potassium resulted in the formation of $3^{2-}$; see Scheme 1.

The spectrum of $3^{2-}$ in THF- $d_{8}$ from reduction with potassium is shown in Figure 2a and that with lithium in Figure 2b. For the complete ${ }^{1} \mathrm{H}$ NMR spectra from each reduction and the COSY spectrum from reduction with potassium, see the Supporting Information. While the chemical shifts of both $\mathrm{K}_{2} 3$ and $\mathbf{L i}_{2} \mathbf{3}$ show the upfield shift consistent with an antiaromatic species, anionic species also show upfield ${ }^{1} \mathrm{H}$ NMR chemical shifts. To understand the contribution of antiaromaticity to the ${ }^{1} \mathrm{H}$ NMR chemical shifts, we calculated the chemical shifts using the GIAO method that was also used for the calculation of the NICS values. The chemical shifts were also calculated with solvent using the polarization continuum, PCM, method, and with the 
Table 2. Experimental and Calculated Shifts for $\mathrm{K}_{2} 3$ and for $\mathrm{Li}_{2} 3$

\begin{tabular}{ccccccc} 
& \multicolumn{3}{c}{$\mathrm{K}_{2} 3$} & & \multicolumn{3}{c}{$\mathrm{Li}_{2} 3$} \\
\cline { 2 - 3 } \cline { 5 - 6 } & expt & calcd $^{a}$ & & expt & calcd $^{a}$ \\
2 & 4.664 & 4.425 & & 4.837 & 6.101 \\
3 & 5.921 & 6.136 & & 5.889 & 6.861 \\
4 & 5.144 & 5.434 & & 5.153 & 6.225 \\
4 & 5.240 & 5.462 & & 5.241 & 6.709
\end{tabular}

${ }^{a}$ Shifts calculated with the GIAO and PCM methods with basis set B3LYP $/ 6-311+\mathrm{g}(\mathrm{d}, \mathrm{p})$ on geometries optimized with the B3LYP/6-31 $\mathrm{g}$ (d) basis set.

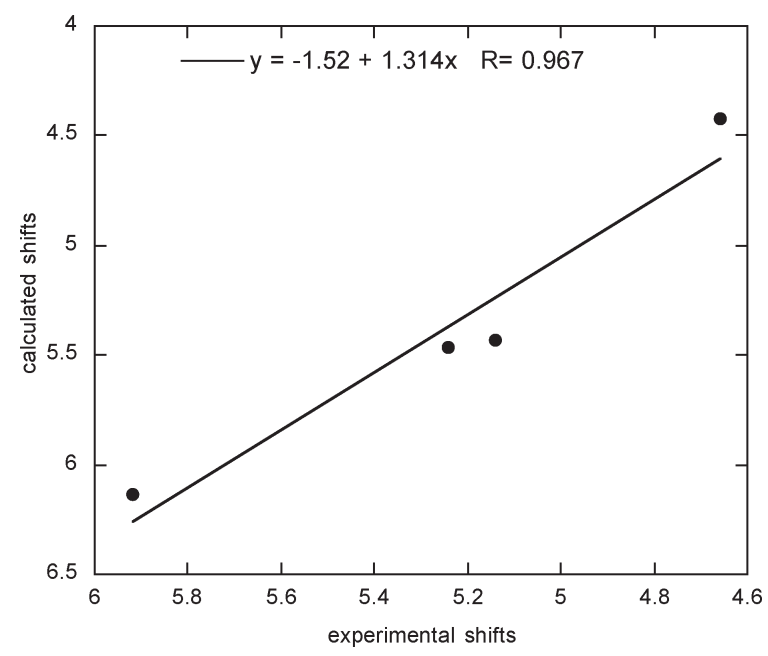

Figure 3. Experimental vs calculated shifts for $3^{2-}$ from reduction with potassium.

lithium or potassium counterions. The experimental and calculated shifts with the greatest agreement are given in Table 2. Figure 3 shows that there is good agreement between the experimental and calculated shift for the dianion reduced with potassium when the shift is calculated with the counterion and with solvent. The agreement is not quite as good for the dianion from reduction with lithium and is best when both solvent and counterion are included in the calculation; see the Supporting Information.

It is clear that there is an effect of the counterion and that the effect is strongest in the 1 position. This would suggest incomplete delocalization that left the greatest electron density on carbon-9. This would be consistent with a pattern of delocalization that preserved the stability of the benzene rings.

Attempted Preparation of the Dianion of Dixanthylidene by Deprotonation. In attempts to prepare antiaromatic dianions by reduction in other systems, such as $\mathbf{5}$, we have found that there is a strong tendency for over-reduction to trianion radicals and tetraanions. ${ }^{29}$ Thus, we set out to determine a protocol for the formation of antiaromatic dianions through deprotonation. Deprotonation of 6, Scheme 2, would give an antiaromatic dianion whose ${ }^{1} \mathrm{H}$ NMR spectrum is known, giving us proof of concept.

While deprotonation to give antiaromatic anions has been problematic, ${ }^{30,31}$ Wan et al. ${ }^{32,33}$ discovered that when deprotonation was done with irradiation, the photoexcited starting
Scheme 2. Tetra-deprotonation of 6

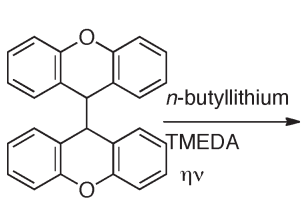

6
$6^{4-}$

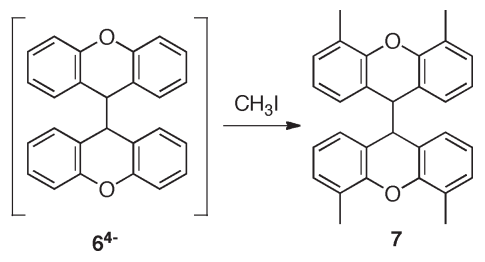

material was substantially more acidic. For example, the antiaromatic suberenyl anion could be formed with much greater ease, including with the use of very weak bases like $\mathrm{D}_{2} \mathrm{O}$. The ease of formation under irradiation is consistent with the observation that the excited states of antiaromatic species are aromatic. ${ }^{34}$<smiles>C1=Cc2ccccc2C(=Cc2ccccc2)c2ccccc21</smiles>

$\mathrm{Li}$<smiles>O=Cc1ccccc1C(=O)c1ccccc1Cl</smiles>

Because we were interested in the direct observation of the dianion via ${ }^{1} \mathrm{H}$ NMR spectroscopy, we chose to examine the deprotonation of 6 with an excess of strong base, $n$-butyllithium/ TMEDA. We anticipated that formation of the dianion would be fairly smooth because the anion of xanthene was successfully generated via excited state deprotonation. ${ }^{35}$ Rather than getting deprotonation at the benzylic positions to give $3^{2-}$, the major product visible in reaction mixture from the quench of the mixture with $\mathrm{CH}_{3} \mathrm{I}$ was 7 , presumably from $6^{4-}$, see Scheme 2, although there was evidence of other methylated species in much smaller amounts as well as unreacted starting material; see the Supporting Information. The low isolated yield of $\mathbf{6}$ is unoptimized and reflects our primary interest in pure product. There is precedent for deprotonation of 9,9-dimethylxanthene to give the dianion, with deprotonation occurring ortho to the oxygen atoms. $^{36}$

In this case, there was no advantage to deprotonation under irradiation because the spectra of the irradiated and dark reaction mixtures were virtually identical; see the Supporting Information. In addition, reaction of the nonirradiated reaction mixture with methyl iodide also formed 7.

We believe that the failure to observe deprotonation to the antiaromatic dianion supports an observation by Budac et al. ${ }^{37}$ in which they attributed the failure to deprotonate 8 to the geometry of the starting material. Deprotonation of $8, R=H$, under photolysis resulted in significant deuterium exchange. However, the derivatives of $\mathbf{8}$ with $\mathrm{R}=\mathrm{CH}_{3}$ or $\mathrm{Ph}$ gave no deuterium exchange. When the proton in the 5-position of 8 was in the pseudoequatorial position, deprotonation would not result in "significant overlap of the developing $\pi$ orbital with the $\pi$ orbitals of the two benzene rings." This is in agreement with the known crystal structure of 6 , in which one xanthyl ring occupies the axial position of the second xanthyl ring system, placing the $\mathrm{C}-\mathrm{H}$ bond to be deprotonated in the pseudoequatorial position; see the Supporting Information for the crystal structure previously reported. ${ }^{38}$ While the similarity of geometry of $\mathbf{6}$ and $\mathbf{8}$ supports the failure of excited state deprotonation in both, the folded geometry of 
8 and related species ${ }^{39}$ could also contribute to its reluctance to deprotonate.

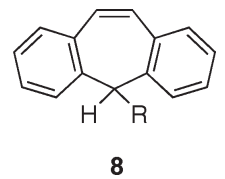

In summary, we report the reduction of dixanthylidene 3 to an antiaromatic heterocylic dianion, which was characterized through ${ }^{1} \mathrm{H}$ NMR spectroscopy. Attempts to form the dianion by taking advantage of the potential excited state acidity of 6 were unsuccessful because the geometry of the starting material failed to allow adequate stabilization of the developing carbanion through its overlap with the $\pi$-system of the benzene rings.

\section{EXPERIMENTAL SECTION}

Reduction of 3 to $3^{2-}$. Dixanthylidene 3 was synthesized by the method of Ault. ${ }^{40}$ Neutral 3 was reduced with lithium following a variation of the procedure of Rabinowitz. ${ }^{41}$ A piece of fresh lithium wire was placed in the upper part of an extended NMR tube which contained ca. $10 \mathrm{mg}$ of 3 . THF- $d_{8}$ was transferred to the evacuated tube. The solution was degassed using the freeze-pump-thaw technique and flame-sealed. The solution was brought into contact with the lithium by inverting the tube. The inverted tube was then sonicated at $0{ }^{\circ} \mathrm{C}$ to remove the oxidized layer on the lithium. Sonication continued until the solution turned to a deep red, ca. $8 \mathrm{~h}$.

Deprotonation of 6 and Formation of 7. $N, N, N^{\prime}, N^{\prime}$-Tetramethylethylenediamine $(3.0 \mathrm{~mL}, 0.022 \mathrm{~mol})$ was added to a solution of $n$-butyllithium in cyclohexane $(2.2 \mathrm{M}, 10 \mathrm{~mL}, 0.022 \mathrm{~mol})$ giving a light yellow solution with a white gelatinous precipitate. This solution was then added to $6^{42}(0.20 \mathrm{~g} 0.552 \mathrm{mmol})$ and irradiated for $18 \mathrm{~h}$ giving a deep red solution. Methyl iodide $(10 \mathrm{~mL}, 0.16 \mathrm{~mol})$ was added at $0{ }^{\circ} \mathrm{C}$ followed by $25 \mathrm{~mL}$ of $\mathrm{H}_{2} \mathrm{O}$. The solution was extracted with $20 \mathrm{~mL}$ of methylene chloride. The organic layer was then extracted with $2 \times$ $20 \mathrm{~mL}$ of $10 \% \mathrm{HCl}$. Solvent was removed from the organic layer under vacuum to give a brown solid. Purification through a silica plug followed by recrystallization from hexanes gave a white solid $(0.012 \mathrm{~g}, 5.4 \%$ yield $):{ }^{1} \mathrm{H}$ $\operatorname{NMR}\left(\mathrm{CDCl}_{3}\right) \delta 7.02(\mathrm{~d}, J=5.8 \mathrm{~Hz}, 4 \mathrm{H}), 6.76(\mathrm{t}, J=7.49 \mathrm{~Hz}, 4 \mathrm{H}), 6.40$ $(\mathrm{dd}, J=7.58 \mathrm{~Hz}, 4 \mathrm{H}), 4.00(\mathrm{~s}, 2 \mathrm{H}), 2.19(\mathrm{~s}, 12 \mathrm{H}) ;{ }^{13} \mathrm{C} \mathrm{NMR}(75 \mathrm{MHz}$, $\left.\mathrm{CDCl}_{3}\right): \delta 151.6,129.1,127.0,125.0,122.0,121.9,50.3,15.7$. Anal. Calcd for $\mathrm{C}_{30} \mathrm{H}_{26} \mathrm{O}_{2}$ : C, 86.09; H, 6.26; O, 7.65. Found: C, 85.67; H, 6.11; O 7.04 .

Computational Methods. Geometries were optimized at B3LYP/6-31G(d) density functional theory levels with the Gaussian 98 and 03 program packages (see the Supporting Information). The chemical shifts were calculated at B3LYP $/ 6-311+\mathrm{g}(\mathrm{d}, \mathrm{p})$ using the GIAO approach with the Gaussian 98 or 03 program packages on the optimized geometries. The nucleus-independent chemical shifts $\left(\operatorname{NICS}(1)_{z z}\right)^{12,23}$ were obtained from the chemical shift tensor perpendicular to the ring for a dummy atom placed $1 \AA$ above the center of each ring.

\section{ASSOCIATED CONTENT}

Supporting Information. Geometries of $1^{2-}-3^{2-}$ and related monoanions, details of the magnetic susceptibility calculations. complete ${ }^{1} \mathrm{H}$ NMR spectral data for reduction of 3 with lithium and potassium, COSY spectrum from reduction with potassium, plots of experimental vs calculated shifts and tables of calculated shifts for dianions with and without counterion, with and without solvent, complete NMR characterization of $7\left({ }^{1} \mathrm{H},{ }^{13} \mathrm{C}\right.$, COSY, HMQC, HMBC data), and ${ }^{1} \mathrm{H}$ NMR spectra of irradiated and nonirradiated deprotonation. ${ }^{1} \mathrm{H}$ NMR spectrum of the reaction mixture from quench with methyl iodide, reported ${ }^{1} \mathrm{H}$ NMR data for $4^{-}$, literature data on the crystal structure of 6 , Cartesian coordinates and total energies for $\mathbf{1}^{2-}, 2^{2-}, \mathbf{K}_{2} \mathbf{2}, \mathbf{L i}_{2} \mathbf{2}$, and related monoanions, complete citations for Gaussian 03 and 09. This material is available free of charge via the Internet at http://pubs.acs.org.

\section{AUTHOR INFORMATION}

\section{Corresponding Author}

*E-mail: nmills@trinity.edu.

\section{ACKNOWLEDGMENT}

We thank the Welch Foundation (Grant No. W-794) and the National Science Foundation (Grant Nos. CHE-0242227 and CHE-0948445) for support of this work.

\section{REFERENCES}

(1) Mills, N. S.; Benish, M. A. J. Org. Chem. 2006, 71, 2207.

(2) Mills, N. S.; Llagostero, K. B.; Tirla, C.; Gordon, S.; Carpenetti, D. J. Org. Chem. 2006, 71, 7940.

(3) Mills, N. S.; Tirla, C.; Benish, M. A.; Rakowitz, A. J.; Bebell, L. M.; Hurd, C. M. M.; Bria, A. L. M. J. Org. Chem. 2005, 70, 10709.

(4) Mills, N. S.; Malinky, T.; Malandra, J. L.; Burns, E. E.; Crossno, P. J. Org. Chem. 1999, 64, 511.

(5) Mills, N. S. J. Am. Chem. Soc. 1999, 121, 11690.

(6) Mills, N. S.; Burns, E. E.; Hodges, J.; Gibbs, J.; Esparza, E.; Malandra, J. L.; Koch, J. J. Org. Chem. 1998, 63, 3017.

(7) Mills, N. S.; Malandra, J. L.; Burns, E. E.; Green, A.; Unruh, K. E.; Kadlecek, D. E.; Lowery, J. A. J. Org. Chem. 1997, 62, 9318.

(8) Malandra, J. L.; Mills, N. S.; Kadlecek, D. E.; Lowery, J. A. J. Am. Chem. Soc. 1994, 116, 11622.

(9) Dahl, B. J.; Mills, N. S. J. Am. Chem. Soc. 2008, 130, 10179.

(10) Dahl, B. J.; Mills, N. S. Org. Lett. 2008, 10, 5605.

(11) Mitchell, R. H. Chem. Rev. 2001, 101, 1301.

(12) Schleyer, P. v. R.; Maerker, C.; Dransfeld, A.; Jiao, H.; Hommes, N. J. v. E. J. Am. Chem. Soc. 1996, 118, 6317.

(13) Dauben, H. J.; Wilson, J. D.; Laity, J. L. In Nonbenzenoid Aromatics; Snyder, J. P., Ed.; Academic Press: New York, 1971; Vol. 2, p 167.

(14) Schleyer, P. v. R.; Puehlhofer, F. Org. Lett. 2002, 4, 2873.

(15) Krygowski, T. M.; Cyranski, M. K. Chem. Rev. 2001, 101, 1385.

(16) Cyranski, M. K.; Krygowski, T. M.; Katritzky, A. R.; Schleyer, P. v. R. J. Org. Chem. 2002, 67, 1333.

(17) Katritzky, A. R.; Karelson, M.; Sild, S.; Krygowski, T. M.; Jug, K. J. Org. Chem. 1998, 63, 5228.

(18) Piekarski, A. M.; Mills, N. S.; Yousef, A. J. Am. Chem. Soc. 2008, $130,14883$.

(19) Gayoso, J.; Ouamerali, O. Rev. Roum. Chim. 1981, 26, 1035.

(20) Mills, N. S.; Llagostera, K. B. J. Org. Chem. 2007, 72, 9163.

(21) Hoshino, M.; Matsui, M.; Imamura, M. Bull. Chem. Soc. Jpn. 1974, 47, 534

(22) Bowyer, W. J.; Engelman, E. E.; Evans, D. H. J. Electroanalyt. Chem. Interfac. Electrochem. 1989, 262, 67.

(23) Fallah-Bagher-Shaidaei, H.; Wannere, C. S.; Corminboeuf, C.; Puchta, R.; Schleyer, P. v. R. Org. Lett. 2006, 8, 863.

(24) Dauben, H. J.J.; Wilson, D. J.; Laity, J. L. J. Am. Chem. Soc. 1968, $90,811$.

(25) Bird, C. W. Tetrahedron 1996, 52, 9945.

(26) Kasmai, H. S. J. Chem. Educ. 1999, 76, 830.

(27) Anastassious, A. G.; Kasmai, H. S. Angew. Chem., Int. Ed. Engl. 1980, 19, 43. 
(28) Olah, G. A.; Prakash, G. K. S.; Liang, G.; Westerman, P. W.; Kunde, K.; Chandrasekhar, J.; Schleyer, P. v. R. J. Am. Chem. Soc. 1980, 102,4485 .

(29) Blakely, T.; Mills, N. Unpublished results.

(30) Breslow, R. Acc. Chem. Res. 1973, 6, 393.

(31) Tolbert, L. M.; Ali, M. Z. J. Org. Chem. 1982, 47, 4793.

(32) Wan, P.; Krogh, E.; Chak, B. J. Am. Chem. Soc. 1988, 110, 4073.

(33) McAuley, I.; Krogh, E.; Wan, P. J. Am. Chem. Soc. 1988, 110,600 .

(34) Gogonea, G.; Schleyer, P. v.; Schreiner, P. R. Angew. Chem., Int. Ed. 1998, 37, 1945.

(35) Wan, P.; Shukla, D. J. Photochem. Photobiol. A 1998, 113, 53.

(36) Wang, H.; Gabbaie, F. P. Organometallics 2005, 24, 2898.

(37) Budac, D.; Wan, P. J. Photochem. Photobiol. A 1996, 98, 27.

(38) Li, P...; Wang, T.-S.; Lee, G.-H.; Liu, Y.-H.; Wang, Y.; Chen, C.-T.; Chao, I. J. Org. Chem. 2002, 67, 8002.

(39) Ikeyama, T.; Kabuto, C.; Sato, M. J. Phys. Chem. 1996, 100, 19289.

(40) Ault, A.; Kopet, R.; Serianz, A. J. Chem. Educ. 1971, 48, 410

(41) Shenhar, R.; Beust, R.; Hagen, S.; Bronstein, H. E.; Willner, I.; Scott, L. T.; Rabinovitz, M. J. Chem. Soc., Perkin Trans. 2 2002, 449.

(42) Nair, C.; Snehalatha, K.; Krishnakumari, B.; Pardhasaradhi, M. Ind. J. Chem., Sect. B. 1992, 31B, 540. 